\title{
PRIMARY CONGENITAL GLAUCOMA; OUTCOME OF TRABECULOTOMY
}

1. MBBS, FCPS

Department of Ophthalmology,

Allied Hospital,

Faisalabad, Pakistan

2. MBBS

Department of Ophthalmology,

Allied Hospital,

Faisalabad, Pakistan.

3. MBBS

Department of Ophthalmology,

Allied Hospital,

Faisalabad, Pakistan.

4. MBBS, FCPS Trainee

Department of Ophthalmology,

Allied Hospital,

Faisalabad, Pakistan.

5. MBBS

Department of Ophthalmology, Allied Hospital,

Faisalabad, Pakistan.

\section{Correspondence Address:}

Dr. Iftikhar Ahmad

Department of Ophthalmology,

Allied Hospital,

Faisalabad, Pakistan

driftakhar96@hotmail.com

Article received on:

15/05/2017

Accepted for publication:

15/07/2017

Received after proof reading:

08/09/2017
Iftikhar Ahmad ${ }^{1}$, Nida Nadeem², Nahdia Ashraf ${ }^{3}$, Muhammad Ahsen ${ }^{4}$, Zubair Ahmad ${ }^{5}$

ABSTRACT... Objectives: To determine the outcome of trabeculotomy in patients presenting with primary congenital glaucoma at a tertiary care hospital in Pakistan. Design: It was a descriptive case series. Place and Duration of Study: This study was conducted at the Department of Ophthalmology, Allied Hospital Faisalabad over 3 years from January 2014 to December 2016. Material and Methods: 45 consecutive children presenting with primary congenital glaucoma were included after written informed consent. These children underwent trabeculotomy. Outcome variable was frequency of successful treatment which was defined as persistent intraocular pressure below $20 \mathrm{mmHg}$ without medication for at least six months and reduction or stabilization of cupping of the optic disc. A predesigned proforma was used to record patient's demographic details along with outcome variables. Results: The mean age of the patients was $17.47 \pm 5.77$ months. There were $28(62.2 \%)$ male and $17(37.8 \%)$ female children with a male to female ratio of $1.6: 1$. It was bilateral in $37(82.2 \%)$ patients. There was significant improvement in the mean intraocular pressure $(12.69 \pm 2.12 \mathrm{vs}$. $25.09 \pm 4.52 \mathrm{mmHg}$; $\mathrm{p}<0.00001)$, horizontal corneal diameter $(11.96 \pm 1.49$ vs. $14.87 \pm 2.03 \mathrm{~mm} ; \mathrm{p}<0.00001)$, axial length $(20.16 \pm 2.51$ vs. $20.69 \pm 2.37 \mathrm{~mm} ; \mathrm{p}=0.0002)$ and cup-disc ratio $(0.30 \pm 0.15$ vs. $0.51 \pm 0.19 ; p<0.00001)$ from baseline at 6 months follow-up after trabeculotomy. Treatment was successful in $39(86.7 \%)$ patients. There was no significant difference in the frequency of successful treatment across age and gender groups. Conclusion: Trabeculotomy is an easy to perform procedure with high success rate of $86.7 \%$ in children with primary congenital glaucoma. The complications observed in the present series were related to surgical skill and technique and were successfully managed.

Key words: $\quad$ Congenital Glaucoma, Primary Congenital Glaucoma, Trabeculotomy.

Article Citation: Ahmad I, Nadeem N, Ashraf N, Ahesn M, Ahmad Z. Primary congenital glaucoma; outcome of trabeculotomy. Professional Med J 2017;24(9):14151419. DOI: 10.17957/TPMJ/17.4052

\section{INTRODUCTION}

Primary Congenital Glaucoma (PCG) is accountable for $0.01-0.04 \%$ of total and $5 \%$ of childhood blindness. ${ }^{1}$ It is a worldwide diagnostic and therapeutic challenge. It is an infrequent, inherited abnormality of anterior chamber angle and trabecular meshwork which results in impediment of aqueous outflow leading to increased intraocular pressure (IOP) and subsequent damage to optic nerve leading to gradual visual loss and blindness if untreated. ${ }^{2}$ Its incidence varies from as high as 1:1250 live births in Roman Slovakian to as low as 1:2000030000 live births in western countries. ${ }^{3,4}$ It is characteristically bilateral $(70-80 \%)$ and is more common in boys $(60 \%)$. It has been associated with parental consanguity. ${ }^{3}$ The pathogenesis is still debatable but is believed to be isolated trabeculodysgenesis with thick, compacted trabecular sheets. ${ }^{4}$ Role of medical therapy is limited and definitive treatment for such patients is surgical. Goniotomy presented by Barkan in 1940s was certainly a great development in the surgical treatment of congenital glaucoma. However, it required considerable surgical experience for delicate ab-interno surgery. ${ }^{5}$ Smith in early 1960 's devised Trabeculotomy which was a relatively easy procedure and didn't require much surgical skill compared to goniotomy. In the 1970's and 1980's trabeculotomy became an established alternative ab-externo procedure in surgical treatment of congenital glaucoma. ${ }^{6,7,8}$ It involves inserting a trabeculotome into the Schlemm's canal, which then tears through trabecular meshwork into the 
anterior chamber. Trabeculotomy is feasible in cases where the opaque cornea prevents good visualization of anterior chamber structures. It is also considered to be a more predictable and technically easier surgery. The procedure does not require surgical gonioscopy skills and is, thus, more similar to trabeculectomy, with a less steep learning curve. ${ }^{6,8}$ Another treatment option is trabeculectomy which is generally employed as salvage procedure after failed angle surgery. However, some surgeons prefer to perform it as primary choice in aphakic glaucoma. ${ }^{8}$ The aim of the present study was to evaluate trabeculotomy in terms of frequency of successful treatment and associated complications.

\section{MATERIAL AND METHODS}

This was a descriptive case series conducted at the Department of Ophthalmology, Allied Hospital Faisalabad over 3 years from January 2014 to December 2016. Sample size of 45 cases was calculated with 95\% confidence level and 7\% margin of error taking expected frequency of successful treatment to be $94 \%$ with trabeculotomy in children with primary congenital glaucoma. ${ }^{9}$ Non-probability, consecutive sampling was done and 45 children presenting with primary congenital glaucoma at Ophthalmology Department of Allied Hospital Faisalabad were included into this study after taking written informed consent. Patient was considered for surgery if 4 of following criteria were fulfilled: (1) typical symptoms (epiphora, photophobia, blepharospasm) (2) cloudy cornea (3) Increased IOP (4) Increased corneal diameter (5) Increase in axial length (6) Deep excavated cup (7) PCG in contralateral eye. We only included patients with primary congenital glaucoma and those with secondary congenital glaucoma were excluded. All these patients had complete ocular examination under general anesthesia including anterior segment examination, measurement of intraocular pressure, corneal diameter, gonioscopy, axial lengths, fundoscopy, retinoscopy where possible. A Limbal based conjunctival flap was reflected above. Following peritomy, wet cautery was applied. Subsequently, a $4 \times 4 \mathrm{~mm}$ lamellar rectangular scleral flap was dissected crossing the grey white border-line zone into clear cornea. Then radial incision was given in the middle of underlying sclera, approximately $1 \mathrm{~mm}$ away from limbus. The Schlemm's canal was located by either scleral cut down via a deep scleral flap or direct un-roofing via a deep scleral flap. To confirm about localization of Schlemm's canal and avoid false passage, 6/0 prolene or nylon suture was entered. The passive entry of suture or prolene in the passage confirmed about proper location of schlemm's canal. Then the trabeculotome was gently passed on either side of incision along the canal for about 5-6 mm, with the other parallel arm of trabeculotome as a guide and the trabeculotome was rotated in the anterior chamber. The trabeculotome was swept back and removed. The same procedure was performed on the other half. Outcome variable was frequency of successful treatment which was defined as persistent intraocular pressure below $20 \mathrm{mmHg}$ without medication for at least six months and reduction or stabilization of cupping of the optic disc. Treatment outcome was noted and was recorded in a predesigned proforma along with demographic details of the patient. All the surgeries were performed by a single consultant and all the pre- and post- operative assessments were performed by a single ophthalmologist to eliminate bias.

\section{RESULTS}

The age of the patients ranged from 10 months to 30 months with a mean of $17.47 \pm 5.77$ months. There were 28 (62.2\%) male and 17 (37.8\%) female children with a male to female ratio of 1.6:1. It was bilateral in $37(82.2 \%)$ patients as shown in Table-I.

\begin{tabular}{|l|c|}
\hline Characteristic & Primary Congenital Glaucoma $\mathbf{n = 4 5}$ \\
\hline Age (months) & $17.47 \pm 5.77$ \\
\hline Gender & $28(62.2 \%)$ \\
\hline Male & $17(37.8 \%)$ \\
\hline Female & \\
\hline Laterality & $37(82.2 \%)$ \\
\hline Bilateral & $08(17.8 \%)$ \\
\hline Unilateral & Table-l. Demographic features of study participants \\
\hline
\end{tabular}

There was significant improvement in the mean intraocular pressure $(12.69 \pm 2.12$ vs. $25.09 \pm 4.52$ $\mathrm{mmHg} ; \mathrm{p}<0.00001)$, horizontal corneal diameter 
(11.96 \pm 1.49 vs. $14.87 \pm 2.03 \mathrm{~mm} ; \mathrm{p}<0.00001)$, axial length $(20.16 \pm 2.51$ vs. $20.69 \pm 2.37 \mathrm{~mm}$; $\mathrm{p}=0.0002)$ and cup-disc ratio $(0.30 \pm 0.15$ vs. $0.51 \pm 0.19 ; p<0.00001)$ from baseline at 6 months follow-up as shown in Table-Il. Treatment was successful in $39(86.7 \%)$ patients as shown in Table-III. There was no significant difference in the frequency of successful treatment across age and gender groups.

\begin{tabular}{|c|c|c|c|}
\hline $\begin{array}{l}\text { Charac- } \\
\text { teristic }\end{array}$ & $\begin{array}{c}\text { At } \\
\text { Presentation } \\
n=45\end{array}$ & $\begin{array}{c}\text { At } 6 \text { months } \\
\text { Follow-up } \\
n=45\end{array}$ & $P$ value \\
\hline $\begin{array}{l}\text { Intraocular } \\
\text { Pressure } \\
(\mathrm{mmHg})\end{array}$ & $25.09 \pm 4.52$ & $12.69 \pm 2.12$ & $<0.00001^{*}$ \\
\hline $\begin{array}{l}\text { Horizontal } \\
\text { Corneal } \\
\text { Diameter } \\
(\mathrm{mm})\end{array}$ & $14.87 \pm 2.03$ & $11.96 \pm 1.49$ & $<0.00001^{*}$ \\
\hline $\begin{array}{l}\text { Axial } \\
\text { Length } \\
(\mathrm{mm})\end{array}$ & $20.69 \pm 2.37$ & $20.16 \pm 2.51$ & $0.0002^{*}$ \\
\hline $\begin{array}{l}\text { Cup-Disc } \\
\text { Ratio }\end{array}$ & $0.51 \pm 0.19$ & $0.30 \pm 0.15$ & $<0.00001^{*}$ \\
\hline
\end{tabular}

\begin{tabular}{|c|c|c|c|c|}
\hline & & $\mathbf{n}$ & $\begin{array}{c}\text { Successful } \\
\text { Treatment (n \%) }\end{array}$ & $P$ value \\
\hline \multicolumn{2}{|l|}{ Overall } & 45 & 39 (86.7\%) & $\mathrm{N} / \mathrm{A}$ \\
\hline \multirow{2}{*}{$\begin{array}{l}\text { Age } \\
\text { Groups }\end{array}$} & $\begin{array}{l}10-20 \\
\text { months }\end{array}$ & 31 & 27 (87.09\%) & \multirow{2}{*}{0.899} \\
\hline & $\begin{array}{l}21-30 \\
\text { months }\end{array}$ & 14 & 12 (85.71\%) & \\
\hline \multirow{2}{*}{ Gender } & Male & 28 & $24(85.71 \%)$ & \multirow{2}{*}{0.809} \\
\hline & Female & 17 & 15 (88.24\%) & \\
\hline \multicolumn{5}{|c|}{$\begin{array}{c}\text { Table-III. Frequency of successful treatment } \\
\text { Chi-square test, observed difference was statistically } \\
\text { insignificant }\end{array}$} \\
\hline
\end{tabular}

The complications observed in these patients were hyphema, Iris prolapse and stripes in descemet's membrane which were noted in 1 patient each but luckily they were well controlled with medication and had no long-term sequel.

\section{DISCUSSION}

In congenital glaucoma, the IOP is elevated due to developmental abnormalities of the trabecular meshwork resulting in impairment of aqueous outflow. Surgical treatment has therefore concentrated on procedures that open the trabecular meshwork ab externo or ab interno, i.e. trabeculotomy or goniotomy, respectively. ${ }^{8}$ In the present study, we evaluated the outcome of trabeculotomy in children presenting with primary congenital glaucoma. The mean age of the patients was $17.47 \pm 5.77$ months with a male to female ratio of $1.6: 1$. It was bilateral in $37(82.2 \%)$ patients. We observed significant improvement in the mean intraocular pressure $(12.69 \pm 2.12$ vs. $25.09 \pm 4.52 \mathrm{mmHg} ; p<0.00001)$, horizontal corneal diameter $(11.96 \pm 1.49$ vs. $14.87 \pm 2.03 \mathrm{~mm} ; \quad \mathrm{p}<0.00001)$, axial length $(20.16 \pm 2.51$ vs. $20.69 \pm 2.37 \mathrm{~mm} ; \quad p=0.0002)$ and cup-disc ratio $(0.30 \pm 0.15$ vs. $0.51 \pm 0.19$; $\mathrm{p}<0.00001$ ) from baseline at 6 months follow-up. Treatment was successful in 39 (86.7\%) patients.

Qayyum et al. (2014) observed similar mean age of 15 months among children presenting at Bolan Medical College, Quetta with similar male predominance (m:f, 1.5:1). They observed similar significant improvement in mean IOP $(30 \pm 5.7$ vs. $12 \pm 5.3 \mathrm{mmHg} ; \mathrm{p} \leq 0.05)$, horizontal corneal diameter (13.06 \pm 0.6 vs. $13.0 \pm 0.5 \mathrm{~mm} ; \mathrm{p} \leq 0.05$ ), axial length $(21.0 \pm 0.8$ vs. $20.9 \pm 0.6 \mathrm{~mm} ; p \leq 0.05)$ and $C / D$ ratio $(0.52 \pm 0.23$ vs. $0.3 \pm 0.21 ; p \leq 0.05)$. They observed successful treatment in $80 \%$ cases. ${ }^{10}$

Ramkrishanan et al. (2015) included Indian children with a mean age of $6.1 \pm 4.1$ years with a male to female ratio of 1.5:1. The IOP values showed a significant reduction from $29.2 \pm 9.7$ $\mathrm{mm} \mathrm{Hg}$ preoperatively to $13.7 \pm 5.3 \mathrm{~mm} \mathrm{Hg}$ postoperatively $(p=0.001)$. They observed frequency of successful treatment to be $73.3 \% .^{11}$

Yalvac et al. (2007) in another similar series in Turkish population reported frequency of successful treatment to be $82 \%$ with a significant decrease in mean IOP from baseline $(21.41 \pm 7.34$ vs. 33.16 $\pm 7.28 \mathrm{mmHg} ; p<0.001)$. They observed post-operative stripes in descemet's membrane 
in $8.4 \%$ cases. $^{12}$ Malek et al. (2012) also observed similar higher proportion of bilateral disease (86.6\%) in Tunisia. They reported similar significant decrease in mean IOP following surgery $(27.2 \pm 5.4$ vs. $12.4 \pm 4.8 \mathrm{mmHg} ; \mathrm{p} \leq 0.05)$ and observed successful treatment in $89.2 \%$ cases. They observed mild hyphema in 4 cases (14.2\%) and localized descemet's detachment in one case (3.5\%). ${ }^{13}$ Saltzmann et al. (2012) included American children with mean age of $11.1 \pm 3.0$ months and reported significant improvement in mean IOP from baseline $(32.7 \pm 1.1$ vs. $9.9 \pm 1.1$ $\mathrm{mmHg} ; \mathrm{p} \leq 0.05)$ with trabeculotomy. They reported frequency of successful treatment to be $78.96 \% .^{14}$

Zhang et al. (2009) reported similar improvement in mean IOP $(29.94 \pm 6.7521 .86 \pm 10.26 \mathrm{mmHg}$; $p=0.004$ ) with trabeculotomy in Chinese children. They however observed only insignificant improvement in $C / D$ ratio $(0.71 \pm 0.24$ vs. $0.67 \pm 0.15 ; p=0.511)$ and corneal diameter (12.58 \pm 1.13 vs. $12.42 \pm 0.93 \mathrm{~mm} ; p=0.574)$. They observed similar frequency of treatment success (86.96\%) [9]. Huang et al. (2016) reported a similar frequency of successful treatment (85.7\%) in Chinese such children. ${ }^{15}$ Ikeda et al. (2004) reported the frequency of successful treatment to be $63.4 \%$ in Japanese such children. ${ }^{16}$

Zetterberg et al. (2015) observed a similar male predominance with a male to female ratio of 1.5:1 among Swedish children with bilateral glaucoma in $70 \%$ cases. Frequency of successful treatment in their series was $83 \% .{ }^{17}$ Badeeb et al. (2008) reported similar significant decrease in mean IOP $(26.7 \pm 10.9$ vs. $14.0 \pm 2.9 \mathrm{mmHg} ; \mathrm{p}=0.0002)$. They reported a similar success rate of $83.3 \%$ for trabeculotomy in Saudi children with Hyphema (18\%), sub-conjunctival hemorrhage (2.6\%), drawn up pupil $(5.1 \%)$, retinal and choroidal detachment (1.3\%) and vitreous prolapse (1.3\%) as the common complication. ${ }^{18}$ Meyer et al. (2000) in a similar study involving German children with mean age of 15.7 months reported successful treatment in $83.3 \%$ cases. They also observed similar improvement in mean IOP $(28.2 \pm 6.7$ vs. $17.7 \pm 6.0 \mathrm{mmHg} ; \mathrm{p} \leq 0.05)$ and mean axial length $(23.9 \pm 2.3$ vs. $22.3 \pm 2.6 \mathrm{~mm} ; \mathrm{p} \leq 0.05)$ from baseline with trabeculotomy. ${ }^{19}$

The results of the present study are thus comparable with the existing studies in local as well as other populations which advocate the routine use of trabeculotomy as preferred surgical procedure in children with primary congenital glaucoma. However, it is worth mentioning, that we followed the patients only for 6 months and Meyer et al. (2000) reported gradual decline in the trabeculotomy success rates over time from $92.6 \%$ after 1 year of follow-up to $83.3 \%$ after 2 yrs., $66.7 \%$ after 3 yrs., and $50 \%$ after 4 yrs. ${ }^{19}$ In Turkey in 2007, Yalvac et al. also reported that the success rates of trabeculotomy declined over time being $92 \%, 82 \%$, and $74 \%$ at 12,24 , and 36 months respectively. ${ }^{12}$ Thus there is need to conduct a similar study with long term followup to further confirm the results. Such a study is highly recommended in future research.

\section{CONCLUSION}

Trabeculotomy is an easy to perform procedure with high success rate of $86.7 \%$ in children with primary congenital glaucoma. The complications observed in the present series were related to surgical skill and technique and were successfully managed.

Copyright(c) 15 July, 2017.

\section{REFERENCES}

1. Chang Ta C, Cavuoto KM. Surgical management in primary congenital glaucoma: Four Debates. J Ophthalmol 2013; 2013:612708.

2. Yu Chan JY, Choy BN, Ng AL, Shum JW. Review on the management of primary congenital glaucoma. J Curr Glaucoma Pract 2015; 9(3):92-9.

3. Khan AO. Genetics of primary glaucoma. Curr Opin Ophthalmol 2011; 22(5):347-55.

4. Moore DB, Oren Tomkins O, Ben-Zion I. Surgical results in management of advanced primary congenital glaucoma in rural population. Ophthalmology 2011; 118:2-3.

5. Mandal A, Chakrabati D. Updates on congenital glaucoma. Indian J Ophthalmol 2011; 59:148-57.

6. Giangiacomo A, Beck A. Pediatric glaucoma: review of recent literature. Curr Opin Ophthalmol 2017; 28(2):199-203. 
7. Desilva DJ, KHaw PT, Brooks JL. Long term outcome of primary congenital glaucoma. J AAPOS 2011; 15:148-56.

8. Yu Chan JY, Choy BN, Ng AL, Shum JW. Review on the Management of Primary Congenital Glaucoma. J Curr Glaucoma Pract 2015;9(3):92-9.

9. Zhang X, Du S, Fan Q, Peng S, Yu M, Ge J. Long-term surgical outcomes of primary congenital glaucoma in China. Clinics 2009; 64(6):543-51.

10. Qayyum A, Baloch RA. Trabeculotomy in primary congenital glaucoma. Pak J Ophthalmol 2014; $30(3): 125-8$.

11. Ramkrishanan R, Mitra A, Abdul Kader M. Surgical and visual outcomes of childhood glaucoma at a tertiary eye care center in south India. Asia Pac J Ophthalmol (Phila) 2015; 4(5):250-8.

12. Yalvac IS, Satana B, Suveren A, Eksioglu U, Duman S. Success of trabeculotomy in patients with congenital glaucoma operated on within 3 months of birth. Eye (Lond) 2007; 21 (4):459-64.

13. Malek I, Attia S, Khairallah I, Baba M, Nacef L, Bouguila $\mathrm{H}$, et al. Outcomes of Trabeculotomy for Primary Congenital Glaucoma in a Tunisian Population. EGS (Copenhagen) 2012; 10:17-22.
14. Saltzmann RM, Reinecke S, Lin X, Cavanagh HD, Whitson JT. Long-term outcomes of a pseudo 360-degree trabeculotomy ab externo technique for congenital glaucoma at children's medical center. Clin Ophthalmol 2012; 6:689-98.

15. Huang JL, Huang JJ, Zhong YM, Guo XX, Chen XX, $\mathrm{Xu} X Y$, et al. Surgical Outcomes of Trabeculotomy in Newborns with Primary Congenital Glaucoma. Chin Med J 2016; 129:2178-83.

16. Ikeda $H$, Ishigooka $H$, Muto $T$, Tanihara $H$, Nagata $\mathrm{M}$. Long-term outcome of trabeculotomy for the treatment of developmental glaucoma. Arch Ophthalmol 2004; 122(8):1122-8.

17. Zetterberg M, Nyström A, Kalaboukhova L, Magnusson G. Outcome of surgical treatment of primary and secondary glaucoma in young children. Acta Ophthalmol 2015; 93(3):269-75.

18. Badeeb OM. Long term outcome of surgical management of congenital glaucoma. J Taibah Uni Med Sci 2008; 3(2):92-103.

19. Meyer G, Schwenn O, Grehn F. [Trabeculotomy in congenital glaucoma: comparison to goniotomy]. Ophthalmologe 2000; 97(9):623-8.

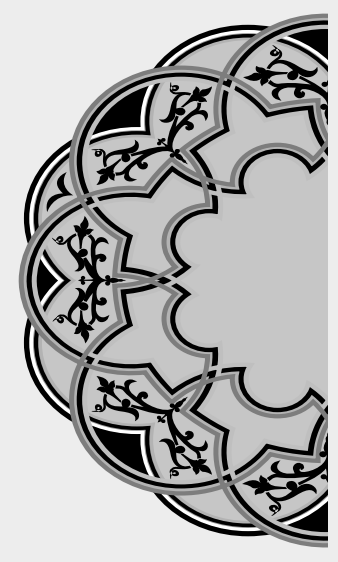

\author{
"Not to know is bad; \\ Not to desire to know is worse."
}

\author{
AFRICAN PROVERB
}

AUTHORSHIP AND CONTRIBUTION DECLARATION

\begin{tabular}{|c|c|c|c|}
\hline Sr. \# & Author-s Full Name & Contribution to the paper & Author $=\mathbf{s}$ Signature \\
\hline 1 & Iftikhar Ahmad & Main Research worker & \\
\hline 2 & Nida Nadeem & Co-author & $n^{4}$ \\
\hline 3 & Nahdia Ashraf & Co-author & Madoptury \\
\hline 4 & Muhammad Ahsen & Co-author & Enetare \\
\hline 5 & Zubair Ahmad & Co-author & \\
\hline
\end{tabular}

